\title{
Phantoms Without a History: Immigrants and Media in Italy
}

\author{
Antonia Cava \\ University of Messina, Messina, Italy
}

\begin{abstract}
In this paper we will investigate the state of Italian media space with respect to the narration of the Foreigner. Desperation and absolute misery seem to be the icon of immigration. The events of which immigrants are protagonists are often out of context and lacking in critical analysis. The media hyper-simplification concurs to a social representation of migration that is currently distorting real-life experiences to such an extent that the spectacularization of migrants brings about problems in terms of their negative self-representations. A distorted, criminalizing and offensive representation is derived. The narrative register alternates victimization and safety. The result is a mediascape made up of suffering, desperation, poverty and fear. This paper aims to show that the invisibility about which so much has been written, as a characteristic of the identity of the immigrant, finds in their negation as media users once again a space they are excluded from.
\end{abstract}

Keywords: immigration, storytelling, television, invisibility

\section{Introduction}

This paper examines the state of Italian media space with respect to the narration of the Foreigner. Let us consider the story of immigration which the Italian media presents in its programming schedule, in the pages of newspapers, and in radio programmes.

Italy is a country with a consistent number of foreign residents (5,014,000 in 2015 according to the Dossier Statistico dell'immigrazione 2015). According to the National Institute of Statistics the number of employed foreigners in 2014 is more than a tenth of the total number of persons employed, with a slightly increasing rate of employment. The employment of foreigners in certain particular job fields constitutes an absolutely precious workforce; consider personal and home care services, as well as badly paid heavy and dangerous jobs. Immigrants in the job market are still heavily disadvantaged. Economic immigration goes on to trigger a process of mobility of a diverse nature such as family reunification which shows that those who find work in Italy decide to put down roots and settle there.

The immigrants constitute a structural part of Italian society and these numbers speak to immigration as a resource for Italy both as a factor in the demographic balance as well as for economic and employment recovery. The process of daily integration is very difficult though.

Foreigners are as yet a silent yet numerous component which makes an important contribution to the creation of wealth in Italy which is economically stagnant. Foreign workers are on average younger, paid less and more flexible. The recognition of the functional role immigration has in the job market does not correspond to equal acceptance with regard to the rights of citizenship: If economic integration is allowed social

Antonia Cava, Research Associate, Department of Cognitive Sciences, Psychology, Education and Cultural Studies, University of Messina. 
immigration seems to yet be denied (Ambrosini, 2011). The politics of integration are still decidedly fragmentary and not well developed (Perna, 2015).

\section{The Immigrant Story: The Italian Case History}

The stereotypes which are presented when speaking about Foreigners are repeated and identical to themselves. Repertories of images and words which, above all in the media, tend to suggest interpretation, opinions, and categories which associate the immigrant with an individual on the periphery of social spaces (Sibhatu, 2004). It almost seems that immigrants are never "normal"; It is no longer possible for our country to ignore the narration of such vivid biographies and ignore the expressions of the cultural wealth of the immigrant community with their heritage of cultural products and images which make up their identity. "Social bodies" bearers of psychological, sentimental and moral meanings; stories that want to be told (Cava, 2014).

Starting from the early nineties, Italian daily newspapers pay constant attention to immigration emphasizing the negative news stories and thus defining it as a serious social problem.

The criminality-clandestine-arrival triangle - underlines the theme of legality, deviance and safety-it summarizes the perception of the problem, with a total absence of the migrants' point of view. The immigrant narrated by the Italian media is almost always socially dangerous, poor, clandestine and Muslim (Ghirelli, 2005; Guadagnucci, 2010; Faloppa, 2011). The events of which immigrants are protagonists are often out of context and lacking in critical analysis. The lack of analysis of the real problems connected to the lives of immigrants in Italy therefore let deviance prevail as the dominant trait in the construction of the image of the Foreigner (Cava, 2011). On the one hand, news stories which depict Foreigners as perpetrators of crime, underlining the element of nationality; on the other hand there is a tendency to present all the stories pertaining to immigration as safety issues. In other words, a distorted, criminalizing and offensive representation is derived. The narrative register alternates victimization and safety.

Over the years little has changed. Gariglio, Pogliano, and Zanini (2010) have reconstructed thirty years of history of our collective imagination through the analysis of the photo-journalistic representation of immigration. A discouraging scenario emerges: during the eighties the lives of the poorest workers were told with compassion; the nineties recounted the spectacular arrivals en masse with tones of desperation and danger; the new millenium should then start to narrate stories of pathways to integration, but the "normality" of immigration doesn't make the news and extreme icons which associate the label of victim or delinquent to immigrants is preferred and the process of stereotyping continues to feed on repertoires of images which are always the same. Rather, the increase in the number of people of different religions and the increase in the number of minors of foreign origin in the schools seems to have amplified fears, dangers and created problems to be solved. The national research study on immigration and asylum in the Italian media which was directed by Morcellini (2009) comes to the same conclusion: The image of immigration presented by the means of information appears to be frozen and immobile, anchored to the same narrative styles. Desperation and absolute misery seem to be therefore, the icon of immigration (Binotto, Bruno, \& Lai, 2012) and this type of visual rhetoric made up of marginalized men and women, who seem to be constantly denied any human rights, risks producing cognitive shortcuts which damage the migrants'lives (Pogliano \& Solaroli, 2012).

In 2012, the National Institute of Statistics in a report on migrants in Italians' daily lives, reveals how $60 \%$ of those interviewed think that the attitude of Italians towards immigrants is suspicious, when not openly hostile (7\%) or indifferent (16\%). Therefore it is not surprising that the most part of those interviewed think it is 
effectively difficult for the immigrant to become a part of our society (80.8\%), 2.4\% think it is impossible and only $16.8 \%$ easy. The tendency to be suspicious and reluctant is not unilateral though, seeing that also the attitude of immigrants towards Italians is prevalently described as suspicious $(53.2 \%)$, indifferent $(20.9 \%)$ or openly hostile (9.6\%).

Many are the Italians who associate the presence of immigrants in Italy to a worsening of some aspects of the quality of life, such as the degradation of the neighbourhoods where they reside (79\%), the increase in crime and illegal activity (72.3\%) and problems of public order and violence $(48.4 \%) .65 .2 \%$ of those interviewed think that the immigrants living in Italy today are too many, over $40 \%$ think that they divert the politicians' attention from the problems of the Italians and evaluate negatively the impact that the continual arrival of new immigrants has on the demographic balance of our country. Regarding the religious aspects, approximately $40 \%$ declares to be very $(17.8 \%)$ or quite in agreement $(22.9 \%)$ in thinking that the coexistance of different religions in our country is a danger.

This data show how, only too often, when we talk about immigration we lose sight of history and the real dynamics of a phenomenon so fundamental for the economy and the Italian political scene, preferring to reconstruct a strong emotional impact. In this way, immigration is no longer geopolitical data to think about, but only a problem to be contrasted, therefore playing on the fears of invasion and degradation.

This aspect is determinant today more than ever in light of the ever closer symbolic association between immigration and insecurity with respect to the attention that media pay to Islamic fundamentalism. This discursive practice ends up influencing the public's approach to suffering, another aspect which connotes the identikit of the "media immigrant" portrayed in a pitiful manner. A desperation made up of violations of human rights, of extreme poverty. The marginalisation of these rejects finds in the welcoming, identification or expulsion centres the representation space preferred by the Italian media.

This is the emotional construction which defines the interaction between migrants and the host society. In the last few years, the "emergency frame" has therefore moved from common criminality to the spectacularization of border controls and the dramatization of Islamic terrorism.

The exceptionality which until now has characterized the story of the life of immigrants becomes the daily routine generating what can be defined as the aesthetics of pity (Chouliaraki, 2006). And the aesthetics of pity cannot but produce a sentimental public at this point which is used to this "hypervisibility of pain". Speaking of which, Dal Lago (2012) invites us to contextualize the behaviour of those who watch the spectacle of pain, tracing a path which puts order in the modulations the eyesight endures before the atrocities over the course of history, and goes as far as to define the indifference of today's public towards cruelty.

Until now we have described the spectacularization of immigration by reconstructing the dynamics of the Italian storytelling of the events of which involve immigrants. The result is a mediascape made up of suffering, desperation, poverty and fear. This emotional narrative construction can only favour distancing oneself from the Other-Foreigner, thus feeding the safety impulse, or at best, generating a compassion which turns into what has already been defined as "the aesthetics of pity".

Let us now turn our attention from the public who witness this particular construction of the Other-Immigrant to the immigrants as the public who witness the media.

Let us then reflect on that normality of immigration which does not seem to interest conversations on immigration at all. Showing the daily and private lives of migrants would allow them to no longer be perceived as phantoms without a history. 
Let us then reverse the perspective and rather think of the role that the industry of culture has in the definition of itineraries of integration. We believe that the invisibility about which so much has been written, as a characteristic of the identity of the immigrant, finds in their negation as media users once again a space they are excluded from. Let us consider the identikit of the immigrant spectator.

In Italy, since 1986, following the establishment of the private TV networks and the competition between public and private media, the Auditel company has been collecting audience data, from all the national TV channels on the air minute by minute. This has been made possible by a technical system which provides for the installation of a people meter, a device connected to the TVs of five thousand families (which make up a sample of about 14 million people) representative of the Italian population. The data is interpreted according to a rank which factors in socio-cultural and economical parameters.

Today Auditel must face new challenges connected to the scenario of technologies which are transforming the television market and the very same way of consuming programs. The makeup of the public is also changing profoundly.

For example, the Auditel sample of TV spectators, being based on the electoral role, contained no foreigners up until two years ago. Therefore the television preferences of foreign spectators were not taken into consideration to the detriment of the television programs dedicated to them.

In reality, Auditel tried to use the Registry lists to gather a sample of the foreign population resident in Italy. They were only able to overcome the technical and juridical obstacles in 2013, when 400 foreign families were added to the 5,200 Italian families. If to compile the Italian sample, the electoral roles continue to be used, for the immigrants, the sample is compiled by the Ipsos research institute in such a way as to accurately respect the many variables of Italian immigration. In this way, the importance of the foreign population in the choices of television consumption, in investors' advertising strategies and in the creation of TV show programming has finally been recognized. Immigrants collaborate in the Italian economy and the importance of understanding their tastes and commercial tendencies has finally been acknowledged (Cava, 2016).

Immigrants are hardly ever thought of as cultural consumers, their free time and entertainment preferences are not taken into consideration. This particular type of consumption in fact can define the context in which a mixed and integrated culture is generated: conferences, shows and museums, readings, websites, the venues of the cities dedicated to social gatherings (Giusti, 2015). It is a question of places to represent universal stories. The web, for example, could have an important role in the transmission of the identity conveyed, the web pages represent a cultural offering which is at the same time a search for roots and also planning for the future. Internet could be one of the most immediate chances for socialization, an instrument able to generate shared knowledge ${ }^{1}$.

\section{Conclusions}

Media production, diffusion and consumption are inextricably linked and have an effect on social practices and political choices. We believe it is essential to rehabilitate the cultural heritage and experience of those who are the protagonists of migratory pathways.

In the restructuring of one's social relations and above all in the redefining of one's own identity within a diverse cultural framework, the space for media consumption is central, where migrants have the possibility to

\footnotetext{
${ }^{1}$ In this paper we are not going to discuss digital issues, since they represent a too varied field that would deserve a deeper look into the themes of digital divide, the digital evolution of Italy and the relationship between new technologies and migrants.
} 
build new biographical pathways. In this sense the collective imagination transmitted by the media, an all-around container of symbols, images and meanings - oriented within a social reality made of shared representations. It is known that the imagination plays a primary role in daily and collective lives, it works as a fundamental element which takes part in the social construction of reality (Berger \& Luckmann, 1966). This is why considering the invisibility of immigrants as cultural consumers seems relevant in the planning of real pathways to integration.

Until now the mainstream media has nurtured the imagination of a public by now used to this hyper-visibility of pain. We need to change the story by breaking the usual narratives which until today have constructed the daily visuals described in the first part of this paper. Cultural consumption is determinant in the essential plans of the migrant, they constitute a key part of the construction of self.

It is part of a process of personalization of their own lifestyles. Their consumer choices are in fact a means to achieving the daily construction of self.

Media consumption is correlated to the way we relate to others. The media allows for the possibility to keep contacts within the "migrating tribe" alive while at the same time interacting with the society chosen as a destination. Italy has yet to address this "need for communication".

The immigrant - as a media user - must be examined as a consumer of a cultural product which translates a certain view of the world, in daily interactions also made up of media images. To share the same media spaces means to come together in a common cultural life, share stories, memories and feelings.

It is no longer possible to ignore the needs and the motivations of the immigrants as subjects of a multimedia market. We are talking about social beings/consumers who choose and use models of both the material and immaterial originating culture and assimilate them in the host countries. In this perspective, the media manage to increase the power of the audiences by representing and promoting identity models.

One of the first steps to recognizing the diversities consists in the redefinition of the spaces given to public opinion which in a multicultural society should always be open to the Other. This approach would allow to thus abandon la rhetoric of terror and the aesthetics of pity which have been discussed above.

\section{References}

Ambrosini, M. (2011). Immigration in Italy: Between economic acceptance and political rejection. Journal of International Migration and Integration, 14(1), 175-194.

Berger, P., \& Luckmann, T. (1966). The social construction of reality: A treatise in the sociology of knowledge. New York: Random House.

Binotto, M., Bruno, M., \& Lai, V. (2012). Gigantografie in nero. Ricerca su sicurezza, immigrazione e asilo nei media italiani (National Research study on immigration and asylum in the Italian media). Raleigh, North Carolina: Lulu Press.

Cava, A. (2011). L'immigrato immaginato. Racconti mediali a confronto (The Imagined Immigrant). Quaderni di intercultura, 3 , $1-14$.

Cava, A. (2014). Ombre migranti: Pratiche discorsive sullo straniero (Migrants as shadows: Discourses on the foreigner). In P. Musarò, \& P. Parmiggiani (Eds.), Media e migrazioni. Etica, estetica e politica del discorso umanitario (Media and Migration) (pp. 157-170). Milano: Franco Angeli.

Cava, A. (2016). L'audience esclusa. Gli immigrati come fruitori mediali (The Excluded Audience). In D. Carzo (Ed.), Culture globali e mediterranee. Migrazioni, integrazioni e noismi (Global and Mediterranean Cultures) (pp. 40-49), Corisco Edizioni.

Chouliaraki, L. (2006). The spectatorship of suffering. Londra: Sage.

Dal Lago, A. (2012). Carnefici e spettatori. La nostra indifferenza verso la crudeltà (Our Indifference to the Cruelty). Milano: Raffaello Cortina Editore. 
Faloppa, F. (2011). Razzisti a parole (per tacer dei fatti) (Racists in Discourses). Roma-Bari: Laterza.

Gariglio, L., Pogliano, A., \& Zanini, R. (2010). Facce da straniero. 30 anni di fotografia e giornalismo sull'immigrazione in Italia (30 Years of Photography and journalism on migration topics). Milano: Mondadori.

Ghirelli, M. (2005). L'antenna e il baobab. I dannati del villaggio globale (The Doomed of the global village). Torino: SEI.

Giusti, M. (2015). Immigrazione e consumi culturali: Un'interpretazione pedagogica (Immigration and cultural consumption: A pedagogical interpretation). Roma-Bari: Laterza.

Guadagnucci, L. (2010). Parole sporche (Dirty Words). Roma: Altreconomia.

Morcellini, M. (2009). Ricerca nazionale su immigrazione e asilo nei media italiani (National research study on immigration and asylum in the Italian media). Sapienza Università di Roma.

Perna, R. (2015). L'immigrazione in Italia. Dinamiche e trasformazioni in tempo di crisi (Immigration in Italy). Politiche Sociali, 1, 89-116.

Pogliano, A., \& Solaroli, M. (2012). La costruzione visiva dell'immigrazione nella stampa italiana. Fotografie giornalistiche e cornici culturali meta-comunicative (The construction of immigration in the Italian Press). Studi Culturali, 9(3), 371-399.

Sibhatu, R. (2004). Il cittadino che non c'è. L'immigrazione nei media italiani (The immigration in Italian media). Roma: EdUp. 